\title{
Double jeopardy and the use of QALYs in health care allocation
}

\author{
Peter Singer, John McKie, Helga Kuhse and Jeff Richardson Monash University, Clayton, Australia
}

\begin{abstract}
The use of the Quality Adjusted Life-Year (QALY) as a measure of the benefit obtained from health care expenditure has been attacked on the ground that it gives a lower value to preserving the lives of people with a permanent disability or illness than to preserving the lives of those who are healthy and not disabled. The reason for this is that the quality of life of those with illness or disability is ranked, on the QALY scale, below that of someone without a disability or illness. Hence we can, other things being equal, gain more $Q A L Y$ s by saving the lives of those without a permanent disability or illness than by saving the lives of those who are disadvantaged in these ways. But to do so puts these disadvantaged people under a kind of double jeopardy. Not only do they suffer from the disability or illness, but because of it, a low priority is given to forms of health care that can preserve their lives. This, so the objection runs, is unjust or unfair.

This article assesses this objection to the use of $Q A L Y s$ as a basis for allocating health care resources. It seeks to determine what is sound in the double jeopardy objection, and then to show that the defender of $Q A L Y s$ has an adequate response to it.
\end{abstract}

We can all agree that when we spend money from the public purse on health care, we should try to get value for money. But there the agreement stops. What is value for money in health care? The outcomes of health care expenditure are so diverse that we need a common standard by which to compare them. The most promising common standard, many believe, is the Quality Adjusted LifeYear, or QALY. In essence, this standard says that the value we get from spending money on health care can be measured in terms of the number of years of life gained, as long as we provide an appropriate rate of discount for periods in which, as a result of ill-health or disability, the quality of life is poor. Several techniques have been used to establish the appropriate rate of discount. The most direct of these, the time trade-off, asks people how long a

\section{Key words}

Resource allocation; health economics; QALY. period of life in the given health condition they would be prepared to trade for one year of normal health. For example, they may say that for one year $\omega$ in normal health, they would give up two years bedridden. Then the appropriate rate of discount for being bedridden is $0 \cdot 5$, because that is the rate of quality adjustment at which a gain of two life-years when bedridden equals a gain of one year in normal health (1).

There are, however, several objections to the use $\overrightarrow{\&}$ of the QALY as a way of measuring the value gained by a given unit of health care expenditure. This article deals with one of them: that for those who are unfortunate enough to have a permanent disability or illness, the use of the QALY as a measure of value gained by health care puts them at an additional disadvantage. The first appearance of this argument in the discussion of QALYs is, as far as we are aware, in an article by John Harris, and we follow him by referring to it as 'double jeopardy' (2). In rejecting the Oregon plan for rationing health care, the United States Secretary for Health and Human Services used a form of the double jeopardy objection (3).

Here is the way Harris puts the double jeopardy argument:

'QALYs dictate that because an individual is $\mathrm{O}$ unfortunate, because she has once become a victim of disaster, we are required to visit upon her a second and perhaps graver misfortune. The first disaster $N$ leaves her with a poor quality of life and QALYs then of require that in virtue of this she be ruled out as a $N$ candidate for life-saving treatment, or at best, that $\underset{\omega}{N}$ she be given little or no chance of benefiting from 0 what little amelioration her condition admits of' (4).

What is sound, and what is unsound, in this $\stackrel{\mathbb{P}}{\rightarrow}$ objection?

\section{Ameliorating the victim's condition}

Harris says that if treatment is allocated on the basis of gaining the most QALYs per dollar, then 'at best' the victim of an earlier disaster will have little or no 8 chance of benefiting from treatment that could ameliorate her condition. Is this right? 
Imagine that Karen is the victim of a disaster - to be precise, she has been injured in a car accident that has left her a paraplegic. She is confined to a wheelchair and has persistent, often severe, back pain. Let us assume that the QALY scale rates two years of life in this condition as worth one year of life in good health. Hence Karen's quality-of-life score is 0.5 . Given her age and general health, her lifeexpectancy is another 40 years. Thus the number of QALYs that her life would be expected to contain, if her condition remains unchanged, is 20 . Now let us assume that a treatment is available for Karen's back pain. She will still be a paraplegic, and need to use a wheelchair, but the pain will go entirely. Her qualityof-life score will rise from 0.5 to 0.75 . The treatment will not change her life-expectancy. Hence the expected QALYs in her life will rise from 20 to 30 .

Another woman, Lisa, was also injured in a car accident, but it can scarcely be called a disaster. If Lisa has no treatment, beyond the initial first aid she has already received, she will be left with a limp, but she will not have any pain from the injury. This gives her, we shall say, a quality-of-life score of $0 \cdot 95$. Her life-expectancy is, like Karen's, 40 years, so if her condition remains unchanged, she has an expectation of 38 QALYs. There is, however, a treatment that will eliminate the limp, returning her quality-of-life score to $1 \cdot 00$, and bringing her posttreatment QALY score to 40 .

For simplicity, let us suppose that Karen's and Lisa's operations cost the same, $\$ 10,000$ each. Is it true that allocating our health dollars so as to produce the largest number of QALY's per dollar will always give Karen - the victim of the disaster that has left her permanently a paraplegic - less chance of treatment than Lisa, who has suffered a relatively minor injury? Obviously not. The $\$ 10,000$ we spend on Karen brings a net gain of 10 QALYs, in other words we have to spend $\$ 1,000$ for each QALY gained. On the other hand the $\$ 10,000$ we spend on Lisa returns us only 2 QALYs, at a cost of $\$ 5,000$ per QALY. So if we spend our health care budget in order to maximise QALYs, we will prefer operations like those that Karen needs to operations like those that Lisa needs; there is no problem of double jeopardy here.

What the example shows is that where amelioration of a disabling or painful condition is possible, a policy of maximising QALYs does not systematically disadvantage a person with a severe disability or illness. The reason for this is simple enough: what is important, from the point of view of using our health care resources effectively, is not the health status of the person at any one point in time (whether that is before the treatment or after the treatment) but rather the change in a person's health status brought about by medical intervention (5). The principle of QALY-maximisation requires directing resources to those groups of patients where the greatest QALY gains can be expected, and this is not necessarily the patients who will have the highest QALY levels at the end of the treatment.

We have not yet, however, tackled the double jeopardy argument on its strongest ground.

\section{Saving the victim's life}

Now let us consider another couple, Michele and Nina, who have also had accidents, and suffered injuries identical to those suffered by Karen and Lisa, respectively, with one important difference: there is no treatment that can help either Michelle or Nina. For the rest of her life, Michelle must expect to be confined to a wheelchair, with persistent, and often severe, back pain; and Nina will walk with a limp for as long as she lives. Initially, it seems that this is likely to be 40 years, in each case; but then each of them is afflicted by a heart condition that, without treatment, will rapidly prove fatal. A heart transplant offers the only hope, at a cost of $\$ 100,000$. What are the QALY implications of providing heart transplants to Michelle and Nina?

For simplicity, let us assume that without the transplant, each will die immediately, and with the transplant, each will live for 40 years. Remember, however, that each year of Michelle's wheelchairbound life is rated at only 0.5 QALYs, whereas Nina's rates 0.95 per cent. So with the transplant, Michelle will have 20 QALYs and Nina 38. If the operation is given to Michelle each QALY gained will have cost $\$ 5,000$, whereas if it is given to Nina, the cost per QALY gained will be only $\$ 2,632$. If those in charge of the hospital budget were to ration heart transplants on the basis of these figures, Nina might receive a transplant whereas Michelle might miss out. Here indeed is a solid basis for Harris's assertion of double jeopardy: because Michelle was once a victim of an accident that left her with a much reduced quality of life, now it seems she is to be visited with a still greater misfortune. She will not receive the treatment she needs to have a chance of continuing to live.

It is easy enough to see what is going on here. As the case of Karen and Lisa made clear, the QALY approach does not take notice of an individual's quality of life per se, but it is sensitive to the incremental QALY gain which a treatment makes. In the case of Michelle and Nina, the gain is composed of two factors: the additional length of life, and the quality of this life. The former is the same for everyone in the two examples, but the latter is very different. Since one year of Michelle's life is equivalent to only half a year of life in full health, whereas the same length of time for Nina equals very nearly a full year in normal health, the QALY approach counts the gain made by the operation as much greater in the case of Nina than in the case of Michelle.

We accept, then, that there is some kind of double jeopardy in these circumstances. Intuitively, this 
seems unfair. But this intuition needs, at least, some scrutiny. If our resources are limited and we cannot save every life that could be saved by some form of health care, is it really unfair to give a lower priority to saving the lives of those with incurable conditions that significantly reduce their quality of life?

As a step towards an answer to this question, consider a final example. Two other patients, Otto and Richard have not been in any accidents, but they have heart conditions just like those of Michelle and Nina. Without transplants they will soon die, with transplants they will be able to continue to live their lives in full health. But Otto also has an entirely separate incurable medical condition that - while it causes him no problems now - will suddenly flare up and end his life. Because of this, his life expectancy is only twenty years, whereas Richard's is almost twice this - to be precise, 38 years.

In QALY terms, the Michelle/Nina pair of patients and the Otto/Richard pair are identical, and if heart transplants were being rationed on the basis of QALYs, preference would in each case be given to the second member of the pair. For those who count only QALYs, it makes no difference whether the smaller number of QALYs gained comes from a lower quality of life, or from a shorter expected lifespan. What about those who oppose the use of QALYs as a basis of allocation of health care? Does it make a difference to them whether QALYs disadvantage a person with a lower quality of life, or with a shorter expected lifespan?

Consistently with his general objection to QALYs, Harris would appear to hold that it is wrong to give preference to someone like Nina over someone like Michelle, and also wrong to give preference to someone like Richard over someone like Otto. In both cases, Harris thinks we should focus on the patients' desire to go on living, rather than the number of QALYs gained. Considering a case in which more QALYs can be gained by giving a lifesaving treatment to one person, who with the treatment has a long life expectancy, rather than to six, who even with treatment have only a short lifeexpectancy, he writes:

'If each of the seven wants to go on living for as long as he or she can, if each values the prospective term of remission available, then to choose between them on the basis of life-years (quality adjusted or not) is in this case to give no value to the lives of six people' (6).

And in a subsequent article Harris says:

'I believe that the value of life can only sensibly be taken to be that value that those alive place on their lives. Consequently, if you and I are of different ages but we both want to live, then it is unfair to prefer your life to mine simply because you are three months younger' (7).
The final sentence of the second passage invokes an $\underset{5}{ \pm}$ example that makes it difficult to disagree with Harris's claim. But he is making it too easy for $\Rightarrow$ himself. If he wants to stand by the claim that the value of life is nothing else but the value that those alive place on their lives, he would have also to $\underline{\bar{E}}$ object to giving the treatment to Otto rather than $\frac{\text { क }}{\frac{1}{6}}$ Richard if they both wanted very much to live, even $\stackrel{\varnothing}{\Phi}$ if the heart transplant could offer Otto only a year oro two, while it still offered Richard 38 years (and, we assume, everything else about Otto and Richard are ${ }_{-}^{\circ}$ the same - it is not the case that Otto needs the time $\vec{\omega}$

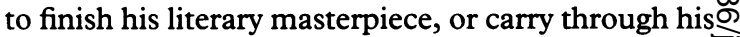
promising research into a method of achieving perpetual peace). Indeed, it isn't clear what basis Harris would have for giving the treatment to Richard rather than Otto, even if the latter would ${ }_{-}^{\omega}$ have only a month, or a week, to live. No doubt $\overrightarrow{+}$ Harris would want to say that there is a thresholdo below which his argument is not valid - but if both? Richard and Otto want to live, it is difficult to seec how such a threshold could be defended, consistently with the general position Harris takes.

\section{More troubling}

Although Harris objects to QALYs because they favour those who will live longer as well as because⿳亠二口 they favour those who have a better quality of life, some may think that the latter case is moreo troubling. But what about a case in which the $\overrightarrow{\vec{O}}$ difference in quality of life is as dramatic as was the 3 difference in life-expectancy in the version of the case of Otto and Richard that we have just? considered? Suppose that Michelle's accident has made her a quadriplegic, and she finds her existence in this condition tolerable, but very much inferior to $\frac{\text { o }}{3}$ life before her accident. In fact, she says - and means it - that she would gladly give up ten years of life as a quadriplegic for a single year in normal health. This makes her QALY score $0 \cdot 1$. She has a life을 expectancy of 40 years. If Nina, who has a similar life expectancy and a near-normal quality of life, needs a life-saving operation, would it be wrong to give herN priority?

Some may say that it would be. But such intuitions should not be accepted uncritically. What ${ }^{\omega}$ could incline us to accept QALY verdicts when the difference in life-expectancy is responsible for the difference in QALY outcomes, but not when the outcome is determined by differences in quality of life? We might be more confident that a difference in $-{ }^{\circ}$ life-expectancy is an objective measure of something, whereas we are suspicious of attempts to $\frac{\stackrel{\rho}{\Phi}}{\mathbb{Q}}$ put cardinal values on people's quality of life. In 0 other words, we know that two years are twice as? long as one year, but we lack conviction that a yearo of life in normal health really is as good as two yearso of life scored as 0.5 . We may know that that is exactly what the figures mean, if the scoring is done? 
correctly, but we may reasonably doubt whether, in practice, anyone can possibly get such calculations right.

Another ground for doubts about giving preference to Nina takes us into more fundamental ethical questions. This is the view that because Michelle has suffered more from her accident than Nina, it is only fair to redress the balance by now conferring a benefit on her rather than on Nina. On the QALY approach this regard for past suffering is not relevant. The QALY approach is wholly forward-looking. All that matters is putting resources where they will achieve the greatest future QALY gain. In contrast, those who argue from a basis of desert or compensatory justice hold that people should not have to endure more than their 'fair share' of human suffering, and we should do what we can to smooth out great differences in the amount people suffer.

This position is supported by Kappel and Sandøe, who distinguish between two different views concerning the span of time within which it is proper to compare the QALY gains and losses of different people:

'The life-time view sees equality as something that concerns a whole life-time. To value the lives of two persons equally we should aim at distributing resources so that each in his life viewed as a whole will have his fundamental interests fulfilled to the same degree as the other person.

The present time view sees equality as something that concerns the present moment. To value the lives of two persons equally we should at any time aim at distributing resources so that they get their actual fundamental interests fulfilled to the same degree' (8).

Kappel and Sandøe support the life-time view. According to this view, since Michelle has had greater suffering as a result of the accident than Nina, then, other things being equal, she is more deserving (though perhaps not overridingly more deserving) of treatment which will improve her subsequent quality of life. To treat people equally we should distribute resources so that each person's fundamental interests are fulfilled to the same degree, including their ongoing interest in enjoying good health. (Note that the greater the time interval between the original accident and the need for lifesaving treatment, the stronger this argument is. If Michelle has already had to endure many years of suffering as a result of her injuries, the case for compensatory preferential treatment is strong; if, however, both Michelle and Nina are still in hospital, just recovering from their injuries, when the need for life-saving treatment arises, the case will be weak.)

In support of the view that a person who has suffered more in the past should get priority in the competition for scarce resources, other things being equal, Kappel and Sandøe point out the appropriateness in other contexts of compensating people for ills which have befallen them. For example, we all think it fair if someone who works extra hours under sufferance, because their special skills are needed, is compensated in the form of extra payment or some extra time off - 'even if, when the time comes for him to be compensated, he is no worse off than other people who are not given extra money or extra time off' (9).

But there are problems with appealing in this way to past suffering in the allocation of health care resources. For example, it is an implication of the life-time view defended by Kappel and Sandøe that someone who is now suffering moderate or mild pain should have a higher priority for treatment than someone who is now suffering intense pain if the former person has suffered more in the past (provided that person's past suffering is greater than the anticipated suffering of the latter person, should he or she fail to receive treatment). In other words, it is an implication of the life-time view that, under certain circumstances, someone presently suffering less should be helped in preference to someone presently suffering more. As Kappel and Sandøe acknowledge, 'this seems counterintuitive' (9).

Kappel and Sandøe are not deterred by this criticism. They suggest that the intuition in favour of helping the person who is presently suffering more may reflect the fact that moderate and mild pain are comparatively tolerable without treatment, whereas intense pain must be treated unless the person is going to suffer badly. In support of this they suggest that if the difference in degree of suffering is lessened we are more inclined to favour the person suffering least (if they have suffered more in the past). 'Imagine that both persons suffer from intense pain but the pain of the first patient is just slightly more intense than the pain of the other patient. In that case it seems more reasonable to treat the person that earlier suffered the most pain' (9).

\section{Timeless view}

However, in giving credence to the intuition that when the difference in degree of suffering is slight it is more reasonable to treat the person who earlier suffered the most pain, Kappel and Sandøe could be accused of begging the question. To the extent that the purpose of health care is to lessen pain and suffering, and to the extent that nothing humanly possible can be done to lessen past pain and suffering, it would seem more reasonable to treat the person who is presently suffering more, since at least this person's suffering can be lessened. Nothing can be done about past suffering, whereas (often) something can be done about present and future suffering. This does not imply a lack of sympathy, nor a callous attitude toward past suffering. With the 
passage of time, present suffering becomes past suffering. Therefore the best way (indeed the only way) to reduce past suffering, as viewed from the future, is to minimise present and future suffering. So if we take a timeless view, this is where our efforts should be directed.

The view we have just been considering is an argument for compensatory justice. This is one strand of the double jeopardy objection, but the double jeopardy objection can also, as we have already seen, be put in a purer form, based simply on the claim that it is unfair that those who are the victims of one disaster should for that reason be put at a further disadvantage by resource allocation decisions. On this view QALYs give the wrong answer, not because they ignore past suffering, but simply because they discriminate against those who are now disabled or living a life of poor quality. John Broome, for instance, points out that the aim of doing the most good may tell us to give lower priority to a disabled person, and then says flatly: 'However, we know this is unfair' (10). Although Broome then goes on to argue that in some cases, this unfairness may be outweighed by a gain in the good achieved, we do not find it self-evident that it would be unfair to give lower priority to the disabled person.

In order to discuss this claim that double jeopardy is simply unfair, let us assume that we have a suitable measure of the value that continued life holds for the person whose life is at stake. This value may be identical to what is now measured by QALYs, or it may be a measure of strength of preference, or it may be something else altogether. For simplicity, we shall refer to it as a person's 'interest in continued life'. If two people both have an interest in continued life, and we cannot offer life-saving treatment to both of them, we have the choice of offering it to neither, or using some method of selecting one of them. Offering it to neither would mean that both patients would die; if we use a method of selecting between the patients, this could be one that relies on chance, or one that employs a principle of selection. In this situation, what course of action is ethically justifiable?

\section{Veil of ignorance}

There are many possible ways of deciding that a social arrangement is ethical or just. Two wellknown examples are Kant's Categorical Imperative, which requires us to act only on maxims that we can will to be universal laws, and the utilitarian proposal that each is to count for one and none for more than one (11). Both suggest some form of impartiality; and John Rawls has drawn on this tradition by suggesting that we can decide whether social arrangements are just by asking if they would be agreed to by rational egoists choosing from behind a veil of ignorance (12). The idea of the veil of ignorance is that it forces an impartial choice by preventing people knowing whether they will be $\underset{F}{F}$ advantaged or disadvantaged by the proposed $\overline{\overline{0}}$. arrangement. So, in this case, we imagine people choosing a basis for allocating health care without $\overrightarrow{\vec{s}}$ knowing whether, at some point in their lives, theywill be in need of health care to prolong their lives; 듬 we imagine also that they do not know whether, if this happens, they will be among those whose $\widehat{\varnothing}$ interest in continued life is low, or among those whose interest is high.

How would two rational egoists choose if they? were faced with a situation in which they each $\overrightarrow{\vec{\omega}}$ needed life-saving treatment, and each had an ${ }_{\sigma}^{\omega}$ interest in continued life, but there was enough lifesaving treatment for only one? Obviously each would $\Phi$ choose the treatment for herself, if he or she could; - but suppose they had to make the choice behind a $\omega$ veil of ignorance, in which they knew the details of $\vec{A}$

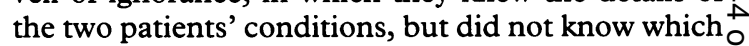
patient they were? They would certainly not choose the option of giving the treatment to neither patient. $\vec{c}$ For this would mean that they would certainly die. In comparison with that prospect, tossing a coin ${ }^{\Phi}$ would at least give them a 50 per cent chance of $\vec{\oplus}$ survival, and so would be preferable. But a randomer method would in turn seem less attractive than aO method of selection that gives preference to the person with a stronger interest in continuing to live. For those choosing the basis for allocating health care will know that, if they choose a random method $\frac{\mathscr{Q}}{\mathscr{Q}}$ of selection in order to avoid discrimination in $\overrightarrow{\vec{P}}$ situations when a treatment cannot be given to 3 everyone, then some with a higher interest in continued life will not receive such treatment. To maximise the satisfaction of their own interests, rational egoists would have to choose a system that gives preference to saving life when it is most in the $\frac{0}{2}$ interests of the person whose life is saved. This means that if QALYs were an accurate way of measuringo when life is most in one's interests, then rational 2 egoists would choose to allocate in accordance witho QALYs. But they cannot do this without building double jeopardy into their principles of distribution. Thus by one widely accepted, and undoubtedly impartial, way of deciding on the justice of principles. of distribution, double jeopardy is not a sign of injustice or unfairness.

The previous argument assumes that the rationalo egoist is faced with a life-and-death decision. Ao similar argument also applies to a case in which two people, at present equally disadvantaged, could each $\stackrel{\odot}{?}$ be given treatment that would improve their quality? of life, but in one case, this would bring the patient back to full health, whereas in the other case, $\stackrel{\mathbb{Q}}{\mathbb{Q}}$ perhaps because of an unrelated pre-existing disability, the treatment would result in a lowero quality of life. Let us also assume that both patientso have a similar life-expectancy, and this is unaffectedo by the treatment. In this situation, since both patients started out from a similar level, the patient 
who can be brought to full health will gain more from the treatment. Assuming that everything else is equal, the calculation has been carried out properly and the treatment can be given to only one patient, a rational egoist choosing from behind a veil of ignorance would choose to give the treatment to the patient who will gain more from it.

This argument from the hypothetical consent of rational egoists is, in our view, an adequate response to the double jeopardy objection, since that objection is based on the assumption that QALYs are unjust or unfair because they lead to double jeopardy. The argument is, however, not new, and Harris has already considered, and rejected it. Before concluding, we shall respond to what Harris has said about hypothetical consent as a defence of QALYs (13). Harris makes three points. The first, citing Ronald Dworkin, is that hypothetical agreement does not provide an independent argument for the fairness of the arrangement that would be agreed to, because:

'... you use the device of a hypothetical agreement to make a point that might have been made without that device, which is that the solution recommended is so obviously fair and sensible that only someone with an immediate contrary interest could disagree' (14).

That is true, by and large, although we would add to the last clause, after the words 'someone with an immediate contrary interest', 'or someone who has fixed ideas about what constitutes "unjust discrimination" and has not reflected adequately on the implications of these ideas'. For while the device of a hypothetical agreement is certainly just an expository device, it can reveal aspects of a situation that were not well understood beforehand.

Harris then argues that even if arrangements are chosen behind a veil of ignorance, that does not ensure they are just or impartial. He offers the example of people choosing a slave-owning society, gambling on being a member of the large number of slave-owners who enjoy living luxurious lives, rather than one of the small number of wretched slaves. But it is difficult to know what to make of this example, because it is not clear if Harris is talking about a world rather like our own, or one in which human nature is quite different from what it is now. If the gamble is really one that well-informed rational egoists would make, then either the number of slaves must be very small indeed, or their lives not so wretched after all - for in the real world, who would think the difference between being the slave of a slave-owner and a citizen of a slave-owning society was so great as to be worth even a one-in-ten chance of ending up as a slave? Moreover, in the real world, a ratio of one slave to every ten free people would certainly not be enough to make the lives of the slaveowners wonderfully luxurious. Of course, some will impatiently wave aside such petty calculations. Slavery is unjust, and we know that much better than we know how many slaves it takes to create luxurious lives for their masters. Indeed, we do, but that is because in the real world, those who support slavery know very well that they are the masters and not the slaves; if there were any uncertainty at all about this, they would not support it. In other words: if we change the nature of human beings enough to make it plausible that rational egoists would choose to allow slavery without knowing if they were to be slaves or masters, then yes, slavery might be just. But as long as human beings stay roughly as they are, rational egoists behind a veil of ignorance would not choose to allow slavery.

Finally, Harris points out that Rawls himself holds that rational egoists behind a veil of ignorance would choose two specific principles of justice, and the second of these principles is that inequalities in wealth and resources are justifiable only in so far as they operate to the advantage of the worst-off members of society. This second principle is, of course, incompatible with the idea of distribution in a way that maximises QALYs. Harris therefore says that if it could be shown that the device of choice behind a veil of ignorance leads to the reverse of Rawls's second principle of justice, this would discredit the plausibility of the device itself. Here, however, we disagree. There have long been good grounds for thinking that in $A$ Theory of fustice Rawls 'cooked the books' in order to derive from his hypothetical device the principles that he believed squared with our considered moral judgments about justice (15). In his own later work Rawls has effectively conceded this point, for he has shifted away from defending the two principles of justice in terms of their derivation from a choice made by rational egoists under conditions of ignorance, and instead has focused on the 'fundamental ideas viewed as latent in the public political culture of a democratic society' (16). If we are right in concluding that rational egoists behind the veil of ignorance would opt for a QALY-based method of allocating health care resources, and if this is incompatible with the principles of justice Rawls claims to have derived from the hypothetical choices of rational egoists, then this discredits Rawls's derivation of the two principles of justice, rather than the device of hypothetical choice itself.

\section{Overall utility}

One final point. We have rejected the claim that QALYs are unjust or unfair because they lead to double jeopardy. This does not necessarily mean that we think that health care should always be distributed so as to produce the largest possible number of health-related QALYs. There is more to overall utility than health-related QALYs, and it is plausible to suppose that tilting the balance of health 
care towards the more disadvantaged members of society will reinforce feelings of concern and sympathy, and lead to a more compassionate society. This in turn may be a society with more commumity feeling and therefore one that provides a higher level of general welfare than a less compassionate society.

In a recent survey of the attitudes of Australians to the distribution of health care, we found that many respondents were ready to depart from QALY maximisation in order to avoid expressing a priority for the treatment of some patients over others, and this may also be explained by a concern for the effects that a direct maximisation approach has on the kind of society we are. For example, when asked whether, among patients who are suffering equally, some priority should be given to those who will be helped most from treatment, only about half ( 53 per cent) of those answering favoured doing so; the remainder thought that those who could become a little better should have the same priority as those who could become much better. Even more striking responses were received to a hypothetical choice between patients who can be helped at low cost and those who are equally ill, but can only be helped at high cost. Overwhelmingly (81 per cent) of respondents favoured equal treatment irrespective of cost, except when the costs are extremely high. Even when presented with a hypothetical example showing that giving priority to low-cost patients would allow more patients to be treated overall, most respondents did not choose to maximise health benefits (17).

It is at least possible that Australians (and no doubt some other nationals as well) consider it important to act in ways that go beyond abstract justice or fairness, instead tilting the balance so that it favours those who would otherwise feel themselves arbitrarily disadvantaged. On these grounds, we could understand a preference for avoiding double jeopardy, even though double jeopardy is not in itself unjust or unfair.

\section{Acknowledgement}

The authors thank the Australian National Health and Medical Research Council which has supported this research through a Public Health Research Project Grant to $\mathrm{Dr} \mathrm{H}$ Kuhse and Professor P Singer.

Peter Singer, fohn McKie, Helga Kuhse and feff Richardson are, respectively, Deputy Director, Research Assistant and Director, Centre for Human Bioethics, Monash University, Clayton, Victoria, Australia and
Director of the National Centre for Health Program Evaluation, Monash University, Fairfield Hospital, Fairfield, Victoria, Australia.

\section{References and notes}

(1) Torrance G W. Measurement of health state utilities for economic appraisal: review. Fournal of health economics 1986; $5,1: 1,30$. If we discount for future life-years, a small additional adjustment of the calculation would be needed. For simplicity, in this article we disregard the issue of discounting.

(2) Harris J. QALYfying the value of human life. Fournal of medical ethics 1987; 13, 3: 117-123.

(3) Daniels N. Rationing fairly: programmatic considerations. Bioethics 1993; 7, 2/3: 227. Daniels is citing a press release by Louis Sullivan of the Health and Human Services Press Office which was issued on August 31992.

(4) See reference (2): 120.

(5) Hadorn D C. The Oregon priority-setting exercise: quality of life and public policy. Hastings Center Report 1991; 21, 3: supplement: 11-16.

(6) See reference (2): 118 .

(7) Harris J. More and better justice. In: Bell J M, Mendus S, eds. Philosophy and medical welfare. Cambridge: Cambridge University Press, 1988: 3.

(8) Kappel K, Sandøe P. QALYs, age and fairness. Bioethics 1992: 6, 4: 297-316.

(9) See reference (8): 315.

(10) Broome J. Fairness versus doing the most good. Hastings Center report 1994; 24, 4: 36-39. See also Broome J. Fairness. Proceedings of the Aristotelian Society 1990; 91: 87-102.

(11) Kant I. The foundations of the metaphysics of morals. In: Kant I. The philosophy of Immanuel Kant. This was first published in $\mathbf{1 7 8 5}$. We refer to page 80 of the edition translated by L W Beck and published in 1949 by the University of Chicago Press, Chicago. The utilitarian dictum is attributed to Jeremy Bentham by John Stuart Mill in Utilitarianism which was first published in 1863 . We refer to page 58 of the edition published in 1960 by J M Dent and sons, London.

(12) Rawls J. A theory of justice. Oxford: Oxford University Press, 1972: ch 1 .

(13) See reference (7): 88-90.

(14) Dworkin R. Taking rights seriously. London: Duckworth, 1977: 151 .

(15) Barry B. The liberal theory of justice. Oxford: Clarendon Press, 1973: ch 9.

(16) Rawls J. The priority of right and ideas of the good. Philosophy and public affairs 1988; 17: 252. See also, Rawls J. Political liberalism. New York: Columbia University Press, 1993.

(17) Nord E, Richardson J, Street A, Kuhse H, Singer P. Maximising health benefits versus egalitarianism: an Australian survey of health issues. Social science and medicine [forthcoming]. 